\title{
A Study on the Attributes Influencing Shipment Delay in Apparel Industry
}

\author{
R.Kamalai ${ }^{1}$ and R.Thenmozhi ${ }^{2}$ \\ \{rtm.afd@psgtech.ac.in ${ }^{1}$, rt.afd@psgtech.ac.in $\left.{ }^{2}\right\}$ \\ Student, Department of Apparel \& Fashion Design, PSG College of Technology, Peelamedu, \\ Coimbatore-641004 ${ }^{1}$, \\ Assistant Professor, Department of Apparel \& Fashion Design, PSG College of Technology, \\ Peelamedu, Coimbatore-641004 ${ }^{2}$
}

\begin{abstract}
Shipment delay is a major problem that affects the relationship between buyer and manufacturer and also affects the transportation cost. This leads to reduce demand, loss of clients, and decline in sales and also create a negative impact on the manufacturer. In this study, corrective measures have been framed and implemented in the industry to overcome the shipment delay. The analysis has been done for 6 different styles of garment production starting from order receiving to shipment delivery. The valuable suggestion have been given to overcome the shipment delay by recruiting junior merchandiser after that the results have been analysed.
\end{abstract}

Keywords: Shipment delay, Raw material, Garment style.

\section{Introduction}

Delay suggests that hindering confinement and postponement of activities. It is unplanned holdup of a regular activity owing to one thing or occurrence that hinder its commencement or persistence. Deviation from repeated lead is mentioned as delay. It occurs because of many reasons, one of main is lead time delay that decrease in throughput have been studied (IRMA 2012). The researcher has been studied and reported that longer the lead time, lesser is the value of data allotment (Lau 2007). It was observed from the (Grain 2014) shipment delay also affects the flow of goods delivery and also reported in their study port congestion leads to shipment delay. (Subramanian, 2013) reported in his study shipment delay is due to bad weather condition.

(Burg 2012) reported in his study shipping delays can be controlled by proper and effective communication between buyer and seller. Few researcher have been studied, the shipment delay may also have occurred due to labour strike (Trefis team, 2015). The many researcher have been studied and reported various reason for shipment delay and there was no study pertaining to technical issue, worker and working system on shipment delay. This study focuses towards identify causes of delay in shipment, identify the factors to be controlled in shipment delay and also provide probable solutions to the delays have been analysed. 


\section{Review of Literature}

There are many reasons for delays in shipment. Key sources for the delaycan be classified as: Practical drawback, Worker connected Problem and System connected Problem. These issues incurred because of some drawback in utilization of equipment efficiently and also less usage of capacities.

The garmenting activities primarily focused on tasks and worker performance is important role. The many causes beneath this class conjointly a number of them are miscommunication and wrong analysis of the records. ${ }^{1}$ This can be mainly linked with the method of activities, inter-departmental communication, time taken in documentation, flow of labour and processes examined.

Delivery on time is the most significant think about these days market to own smart reputation and survival with good market share during this economical world. To keep up-todate dynamic market conditions recently one must be able to get a lot of the quickest commerce merchandise

on sale throughout season. While its attractiveness lasts and similarly eliminate lines that don't seem to be widespread and become drain on resources. ${ }^{2}$

There are reasons for delay - Lack of Resources such as (Man, Machine, and Material), client internal communication is not clear, gap in external communication, gap in regular modification from the client importance and internal rejections.

Reducing lead times is simply attainable by elimination of process, compression of process, incorporation (re-engineering boundaries between sequent practices), correspondence (operate practices in parallel), right order in on-time, complete and correct goods delivery. Attaining this performance systematically requires a vast quantity of effective correction. Customers, on the other hand, may not be aware of operational execution. After all, customers anticipate receiving what they ordered when they require it.

To realize an ideal demand from your client's purpose of view involves abundant more: Consumer satisfaction is driven by prompt fulfilment of customer demands, whereas ordering excess inventory affects the bottom line. Inventory visibility at the provider, in transit, and the warehouse, as well as real-time aggregated order coverage.

In today's world, businesses must be aware of what the customer required and how to obtain it. Spread order controlling streamlines the fulfilment process by organising the following factor such as order aggregation and prioritisation: This entails the selection of orders and their planned execution in order to support the importance and priority of the orders.

Sourcing is to meet current demand, which includes retailers, distribution centres, and suppliers. To generate purchase orders for further supplies as needed. Prepare for the future with a demand statement to ensure that the correct product is delivered at the exact time.

Programming and shipping-efficiently route orders to customers, retailers, partners and distribution centres to attenuate delivery time and storage prices. Inventory shortages, potential customer service issues, and delivery challenges must be tracked so that enough time and information is available to place new orders, replace, reroute and interact with consumers.

Reporting is the key performance metrics, establish targets for on-time deliveries, cash-tocash cycle time, inventory turns and statement precision.

Higher-margin service orders continue to take priority over lower-profit goods sales. Expect recruit, installation, and support revenues to continue to rise margin. It result, service order requirements such as dispatch, availability, project accounting and programming may 
become more critical. The stakeholders want to be able to change order attributes at different stages in the order process. ${ }^{3}$

Organizations are pursuing centralised administration of those order processes as method explosion increases around the order management cycle, ethics for core and reusable processes will emerge alongside developments in beats per minute tools and internet services. Within the order management cycle, it is necessity for various neutral contact points and maturing of middleware platforms encourages businesses.

This new concept results to growing acceptance of knowledge such as customer, product and also supplier. The OMC equation will be completed by matching of master information with reusable order processes, resulting in the importance of the order.

Human characteristics influence garment pre-production operations. Furthermore, several important chain features share a lot of similarities by garment pre-production operations are tackled explicitly and decisively. Reverse planning is the process of carrying operations backward towards delivery date. Garment pre-production is a well-ordered samples, resources are transferred from one to the next project.

Traditional work environments place a premium on "not being late," but they don't encourage the development of new ideas on a consistent basis. When valuing the length of a task, people frequently consider the impact of unforeseen work stoppages and include a hidden safety.

An extra five days could be built into a ten-day project. It's quite inexpensive to include this safety feature but because it's concealed, its usefulness is mislaid. The general trait is to postpone the start of task until the last possible moment, therefore accumulating in the protection buffer.

Unfortunately, if the task is interrupted because there is insufficient time for improvement. Uncertainty a work can be calculated in 10 days, it is likely to take less time. This is frequently as a result of people's ability to simply alter their near of energy to keep themselves occupied throughout the day.

Maximum people build a multi-project situation and have to stop working on one activity in order to make progress on another assignment in another scheme. It results in lack of focus and strength. In order to keep as many customers happy as possible, resources tend to migrate between comes in reaction to the most recent, loudest client demand.

The main reason for multitasking is goal of exhibiting advancement as many active arrives as possible to finish on time. This is frequently due to the fact that early finishes are rarely satisfied.

People are concerned their future approximations being slashed created on their prior performance in this environment, so they discreetly enjoy the pause and formally end on time. In an extremely project, the serious chain is the longest sequence of dependent activities. Due to the project structure or limited resources, activities will be reliant on one another.

In an environment of extreme unpredictability, critical chain could be a game-changer for speeding labour flow through multi-project pipelines. As a result, it considerably simplifies the management of deliveries.

Definitely, skilled project managers rely on components of key chain concepts automatically when creating, and mastering them is synonymous with success. Reduce the total labour in the execution rather than as soon as reasonable, and free up work to support the provision of the most overburdened resources. Place buffers, or chunks of protecting time, where they'll be most effective. ${ }^{4}$ 
To improve project performance by changing people's behaviour (procrastination, multitasking, unneeded sharpening of already completed work, etc.). The truth is that policy modifications after that can stretch you significantly well results.

Replace metricing that relies on separate activities finishing on time with metricing that focuses on low-add development. Order a minimum amount of protected time in each scheme, often one-fifth of the entire number of tasks, to ensure a continuous flow of librae project due dates, which are sacred and can only be changed by top management. ${ }^{5}$ There are various reengineering ideas that can be used to shape the work approach and achieve significant improvements in quality, cost and time management.

Shipment delay is a problem in which the action of shipping goods not in on time. It is annoying for clients when their shipment not received on time. The causes and effects that would clearly explain the root of this problem.

Shipping and logistics agencies should constantly deliver their packages in time, delivery delays gives them a low satisfaction rating. To resolve the problems in delay of the shipments and its causes. The traffic is the causes for shipment delay and random customs inspection are sometimes causing delays in shipments/packages.

Lack of training in workers results, the rate of delivering of the packages will be low since they did not know how to perform their jobs assertively.

\section{Methodology}

- Observation of workflow for each style

The 6 different styles of kid's t-shirt of the buyer TAC as shown in fig 2. The work flow of the order from raw material order placement, PP sample development, size-set sample development, lab-dip approval, sample approval, cutting, printing, embroidery, sewing to packing was observed and noted. The time taken for raw material arrival has been scheduled and simultaneously sample was developed. The order status of all the 6 styles were observed and recorded in the spreadsheet for future references. Each department activities, errors, delays were recorded in the spreadsheet systematically.

- Time and action plan

Fig 4 shows the order status. By monitoring this spreadsheet, the current status of the particular style can be reviewed. It was observed from the above work flow observation spreadsheet the status of raw material sourcing to packing.It was also observed from the table various letter indication that shows difeerent activities happening in the concern departments. In the spreadsheet ' $C$ ' denotes completion of process, ' $A$ ' denotes Accept, ' $P$ ' denotes process and ' $\mathrm{X}$ ' denotes non completion of process.

- Comparison of time and action plan with deviated time

These problems were found to occur most frequently for all the styles. This delayed the delivery date. The comparison between the time and action plan and actual process flow has been compared in order to identify the deviated time and department that causes delay in the shipment delivery. The workflow observation table that has the actual workflow particulars is compared with the time and action plan table. This gives the detailed cause for shipment delay.

- Identification of the problem 
Based on the comparison, the areas causing frequent shipment delay has been identified. Causes for shipment delay is shown in fig 3.(ie) Improper preproduction sample, improper scheduling of embroidery machine space, embroidery machine breakdown, unavailability of actual fabric for sample development, lab dip approval delay, fabric shortage during production and identification of corrective measures for the problem. In order to overcome the distinguished shipment delay, corrective measures must be taken to prevent the similar delays in further orders. The outlined corrective measures are as follows. Develop the infrastructure of the company such as embroidery unit that may reduce the shipment delay caused due to embroidery. The junior merchandisers can be recruited for follow up of sample development process. Based on the issues identified, these corrective measures have been framed to overcome the shipment delay in the industry.

- Implementation

The corrective measure to overcome the delay in sample development has been implemented. The individual junior merchandisers for the sample development process has been recruited for three styles and the result has been inspected.

\section{Results and Discussion}

\section{- Observation of workflow for each style}

Fig 5 shows the work flow of an order. By observing the process of 6 different styles, elaborate concept of the industrial working system has been identified. Based on the observed work flow, detailed analyse of the order and issues faced in the shipment has been understood. The time and action plan has been framed in the spreadsheet before commencing the order. This contains the planned time for each process in the order. The time and action plan have the detailed record of the order and delay caused by each department. Based on the time and action plan, delays are identified specifically and elaborately.

- Comparison of time and action plan with deviated time

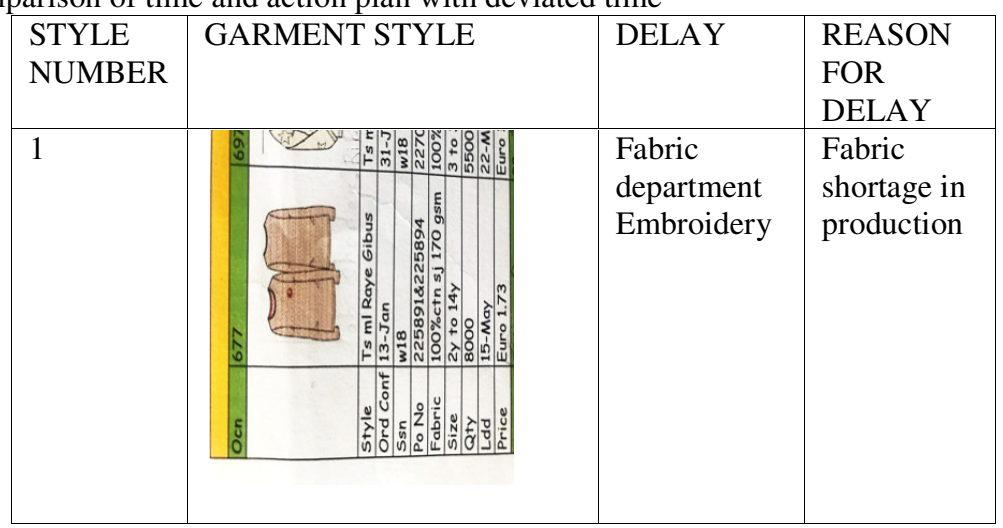




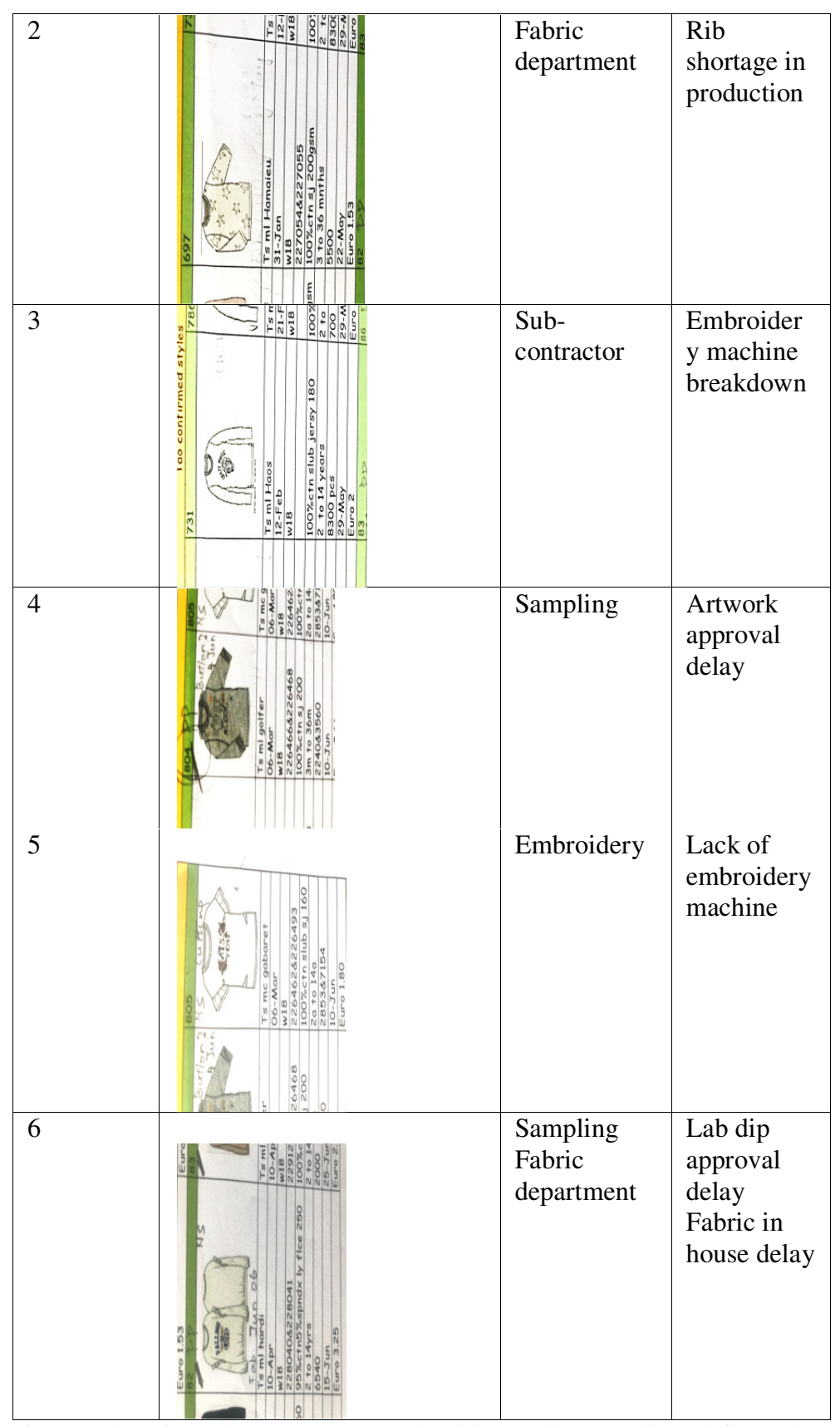

The time and action plan are compared with the actual workflow chart and the deviations are observed and analysed. After framing the time and action calendar, the reasons 
were identified and analysed for each department. It was found that there is a lack in follow up of various process and also found there was no person have been appointed for follow ups.

- Identification of corrective measures for the problem

Based on the identified issue, corrective measures has been discussed with the superiors. The development of the infrastructure has been framed and also recruitment of junior merchandiser to handle the sample development and embroidery process.

- Implementation

Junior merchandisers has been recruited for the sample development process for three styles in order to overcome the delay caused in sampling. The junior merchandiser took utmost care in developing the sample on-time with required approvals. As a result, delay caused in the sample development were eliminated to a great extent. The junior merchandisers were able to take immediate actions to solve the raised issue and avoid causes of delay. After that the delay due to embroidery and sample development has been controlled.

\begin{tabular}{|c|c|c|c|c|c|c|c|c|c|c|}
\hline \multicolumn{4}{|c|}{ Merchandisng } & \multicolumn{7}{|c|}{ status } \\
\hline 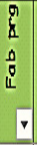 & $\begin{array}{l}\underline{E} \\
E \\
E\end{array}$ & $\frac{y}{12}$ & 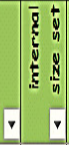 & $\begin{array}{r}5 \frac{5}{6} \\
\frac{5}{0} \\
\frac{5}{8} \\
\end{array}$ & 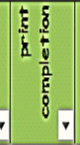 & 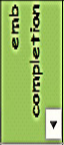 & $\mid \begin{array}{l}28 \\
\frac{8}{6} \\
\frac{6}{6}\end{array}$ & 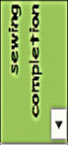 & 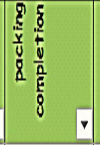 & $\begin{array}{l}y \\
y \\
\frac{y}{b} \\
y \\
y \\
y\end{array}$ \\
\hline c & $p$ & $A$ & $A$ & over & over & over & 7920 & 4800 & & \\
\hline c & p & A & A & over & $x$ & $x$ & 5650 & 5650 & OVER & \\
\hline c & $P$ & A & $A$ & 8657 & $x$ & & & & & \\
\hline c & P & A & A & over & $x$ & over & & & & \\
\hline c & p & $A$ & 09-Jun & & $x$ & & & & & \\
\hline c & p & 01-Jun & $A$ & 8691 & $x$ & & & 3979 & & \\
\hline c & P & A & 13-Jun & & & & & & & \\
\hline c & P & 12-Jun & 21-Jun & & $x$ & & & & & \\
\hline c & P & 12-Jun & 20-Jun & & & & & & & \\
\hline$x$ & P & & 10-Jun & & $x$ & & & & & \\
\hline$x$ & p & & 22-Jul & & & & & & & \\
\hline$X$ & P & & 24-Jul & & $x$ & & & & & \\
\hline
\end{tabular}

Fig :2 Garment style and reason for defect 


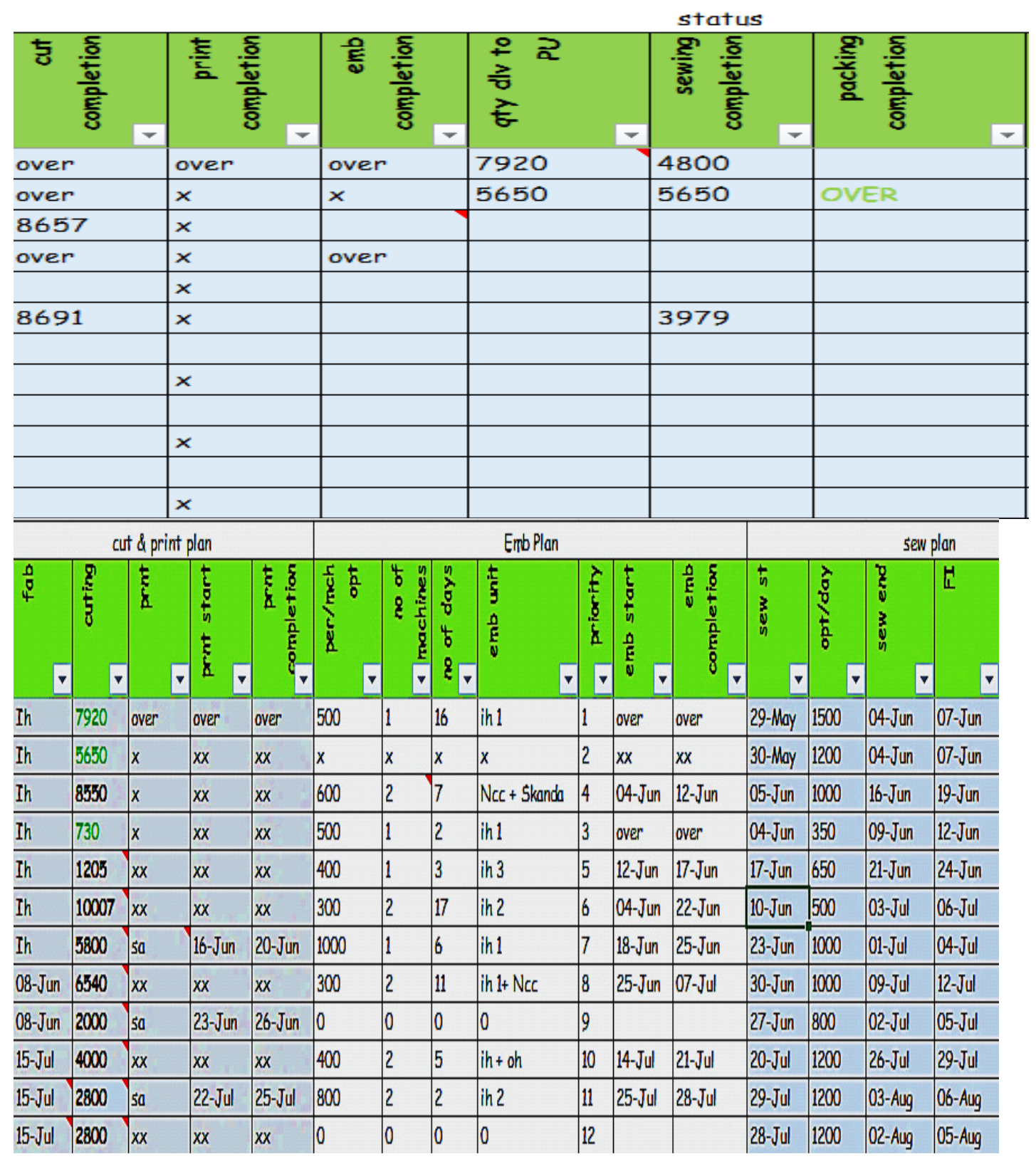




\section{Conclusion}

Shipment delays are one of the most inconvenient aspects of running a business. In order to handle shipment delays, proper planning and experience are viewed as important. To survive in the very competitive market shipment delay should be eliminated. Based on the research carried out in the industry, delays were found in the embroidery and sampling department. Valuable suggestions have been given in order to reduce the delay in shipment. By implementing the suggestion considerable amount of delay have been eliminated in the sampling department.

\section{References}

[1] Chandan JIT S, Statistics, vikas Publishing house pvt ltd. 2000,2 $2^{\text {nd }}$ ed; New Delhi: 12, p.263.

[2] Krishnaswami K N, Appa iyer Sivakumar, Mathirajan M, Management Research Methodology, New Delhi: Dorling Kindersley (India) Pt. Ltd. 2008, $2^{\text {nd }}$ ed Ch.7, P.163.

[3] Jana, Prabir, Supply chain Dynamics in India n Apparel Export Manufacturing: A critical Chain Approach. .2001

[4] Sunil Chopra, Peter Meindl, Supply Chain Management, Delhi: $3^{\text {rd }}$ ed.Pearson Education (Singapore) Pt. Ltd. 2004,

[5] Jeremy A. Rosenau/David L. Wilson, Apparel Merchandising, $2^{\text {nd }}$ ed; New York: Fairchild Publications, Inc.

[6] Information Resources Management Association: Supply Chain Management: Concepts, Methodologies, Tools, and Applications, (2012)

[7] Lau, J.S.: Information Sharing in Supply Chains: Improving the Performance of Collaboration. , (2007).

[8] Garin, J. Manila's Port Congestion Issue: the Search for Systematic (2014).

[9] Subramanian, C.UPS Blames Bad Weather, More Packages and Online Delay of shipments: Causes, Effects, and Recommended Solution shopping for Delays. (2013).

[10] Burg, N. Common Shipping Delays And How To Avoid Them. Retrieved from (2012) 